\title{
Intrauterine cytomegalovirus infection: a possible risk for cerebral palsy and related to its clinical features, neuroimaging findings: a retrospective study
}

\author{
$\mathrm{HXu}^{\dagger}, \mathrm{L}_{\text {Zhang }}^{\dagger}, \mathrm{XY}$ Xuan, M Zhu, J Tang ${ }^{*}$ and XK Zhao ${ }^{*}$
}

\begin{abstract}
Background: Abundant clinical evidences indicate that the increased risk of cerebral palsy (CP) may be associated with the intrauterine exposure to maternal infection. Cytomegalovirus (CMV) is a common cause of CP. However, little is known about the relationship between the intrauterine exposure of the fetus to CMV infection and CP. This study aims to explore the relationships between intrauterine CMV infection and clinical symptoms, classification, intelligence development and brain neuroimaging findings in children with CP.

Methods: In this study, 147 children with CP in recent 6 years were retrospectively analyzed (average age: $14.76 \pm$ 3.07months; sex (M/F): 103/44). 148 children had CMV IgG and IgM positive sera identified by TORCH examination were selected as the control group (average age: $15.10 \pm 3.21$ months; sex (M/F): 102/46), which also undergo the examination of CMV-DNA in urine. The age and sex of children in the control group were matched with those in the CP group. CMV-DNA in urine was detected by CMV fluorescence quantitative PCR, and t-test was performed to analyze the number of copies. For the CP group, standardized rehabilitation treatment was performed and the function of gross motor was evaluated by GMFM scale before and after treatment. The Gesell developmental scale (GDS) was used to assess the level of intellectual development. The classification of CP was conducted and the results of magnetic resonance imaging were analyzed. Finally, the correlations between the copy number of CMV-DNA and the clinical characteristics of children with CP were evaluated by the method of Pearson and Spearman correlation analysis.
\end{abstract}

Results: The level of CMV infection was negatively correlated with the developmental quotient (DQ) of children with CP. Negative association was found between the level of CMV infection and the level of the gross motor development. The level of CMV infection was positively related with the occurrence probability of spastic quadriplegia. However, no associations were found between the abnormalities of brain tissue and the number of CMV copies. Moreover, CMV infection might add the difficulty of the rehabilitation treatment.

Conclusions: CMV infection is a risk factor for the occurrence of CP in children. Pregnancy examination should be strengthened. Early detection and control of CMV infection may contribute to the rehabilitation of children with CP and reduce the disability and social burden.

Keywords: Cerebral palsy, Cytomegalovirus, Mental deficiency, Pediatric

\footnotetext{
* Correspondence: 58503098@qq.com; 240321748@qq.com

${ }^{+} \mathrm{Xu} \mathrm{H}$ and Zhang $\mathrm{L}$ are co-first authors.

Department of Rehabilitation, Children's Hospital of Nanjing Medical

University, Nanjing, China
}

(c) The Author(s). 2020 Open Access This article is licensed under a Creative Commons Attribution 4.0 International License, which permits use, sharing, adaptation, distribution and reproduction in any medium or format, as long as you give appropriate credit to the original author(s) and the source, provide a link to the Creative Commons licence, and indicate if changes were made. The images or other third party material in this article are included in the article's Creative Commons licence, unless indicated otherwise in a credit line to the material. If material is not included in the article's Creative Commons licence and your intended use is not permitted by statutory regulation or exceeds the permitted use, you will need to obtain permission directly from the copyright holder. To view a copy of this licence, visit http://creativecommons.org/licenses/by/4.0/ The Creative Commons Public Domain Dedication waiver (http://creativecommons.org/publicdomain/zero/1.0/) applies to the data made available in this article, unless otherwise stated in a credit line to the data. 


\section{Background}

Cerebral palsy (CP), a common and significant physical disability, is defined as a group of permanent disorders, which is caused by the non-progressive disturbances of the developing fetal or infant brain [1-4]. CP is mainly identified by a range of motor problems including the movement and posture disorders, which cause the limitations in mobility [5-7]. Moreover, the accompanying neurological and developmental disorders of CP including disturbances of cognition, behaviour, communication, sensation, perception and epilepsy, secondary musculoskeletal problems, which may also have a greater effect on the quality life of children with CP $[8,9]$.

Maternal infections during the pregnancy is a common cause of CP [10-12]. Previous studies demonstrated that the intrauterine exposure to infection, particularly cytomegalovirus (CMV), might be responsible for most cases of post-neonatally acquired CP [13-15]. The maternal infection-related factors are considered as risk factors for the subtype spastic hemiplegia $C P$, but not for the spastic diplegia, tetraplegia, or dyskinetic CP [16]. In addition, other previous studies showed that the maternal infections were involved in causing spastic CP while the neonatal infections might be associated with the bilateral spastic and dyskinetic CP $[13,17]$. The inflammatory in the fetus is known as fetal inflammatory response syndrome, which can be activated by the maternal infection and is mediated by different cytokines [18]. The fetal inflammatory response syndrome can induce neonatal white matter injury, which is a cause of fetal or neonatal injury that leads to motor impairment of $\mathrm{CP}$ in pretermborn children [19].

Substantial evidences demonstrate that both direct infection and infection-triggered damage can elicit the brain inflammation and innate immune response, which are closely associated with both acute and chronic brain disease in the newborn $[20,21]$. Therefore, exposure to neonatal infection can lead to an infection-related inflammatory response, which is a great contributor to the injury of the brain [22, 23]. In addition, previous studies showed that the lesions of white matter in the neonatal brain were the most important identifiable risk factor for CP $[24,25]$. CP is often caused by the damage of the developing brain [26, 27]. The intrauterine infections can lead to the release of inflammatory cytokines, which may contribute to the brain white matter lesions and $\mathrm{CP}$ [28-30]. The damage of white matter in the brain can be also caused by the cytokine in the amniotic fluid, which is associated with $\mathrm{CP}$ for children born at term [31, 32]. Moreover, previous neuroimaging studies suggested that the infection was associated with the cerebrovascular ischemia, which might lead to the white matter lesion of the cortical or subcortical brain regions, which was also an important cause of motor impairment of CP [4, 33]. An increased risk of brain abnormalities was found in the infants with CMV, which resulted in severe damage to the developing brain of children with $\mathrm{CP}[22,34]$. However, little is known about the relationship between the intrauterine cytomegalovirus infection and the clinical features, neuroimaging findings of $\mathrm{CP}$. Therefore, more informations about the associations between the causes of $\mathrm{CP}$ and the infection in the perinatal period are needed.

The aims of our study were to determine whether CMV was a possible risk for cerebral palsy and whether CMV was related to the clinical features, neuroimaging findings of children with CP. Therefore, the clinical characteristics and CMV-DNA in urine of were detected in the group of children with CP and the control group. Differencs between groups and the relationships between $\mathrm{CMV}$ and the clinical features, neuroimaging findings were evaluated.

\section{Methods \\ Participants}

This study retrospectively analyzed the children with CP diagnosed for the first time in the rehabilitation department of our hospital from January 2011 to December 2016. Gender- and age-matched children with CMV IgG and IgM positive sera identified by $\mathrm{TORCH}$ examination were collected as the control group. In addition, CMV-DNA in urine of these children were also collected. This study was approved by the ethical commission of Children's Hospital of Nanjing Medical University (Program number (81,501, 946): Version 1). Additionally, consents were obtained from parents or guardians on behalf of participants.

The diagnostic criterias of CP consisted of four necessary conditions and two reference conditions [35]. Necessary conditions: (1) central dyskinesia appeared uninterruptedly; (2) abnormal development of movement and posture; (3) abnormal development of reflex; (4) abnormal muscle tension and muscle strength. Reference conditions: 1) pathological basis leading to CP; (2) brain imaging evidences (magnetic resonance imaging (MRI)).

Inclusion criterias for participants were as follows: (1) children who met the diagnostic and typing criteria of $\mathrm{CP}$ and did not receive any treatment before the diagnosis; (2) CMV-IgG and IgM in the serum of mother was positive identified by $\mathrm{TORCH}$ test during pregnancy, CMV-IgG and IgM in the serum of children was positive identified by TORCH test, and the urinary CMV-DNA data was also collected; (3) CMV infection was not treated with antiviral drugs; (4) all patients received standardized rehabilitation treatments after the diagnosis, such as neurodevelopmental stimulation, muscle spasm/muscle excitation, cerebral circulation, meridian leveling, magnetic therapy, brain ultrasound, biofeedback, muscle strength training and neurotrophic drugs in the 
rehabilitation department of our hospital; (5) MRI data were collected at the average age of $14.76 \pm 3.07$ months for children with $\mathrm{CP}$ and at the average age of $15.10 \pm 3.21$ months for the control children.

Exclusion criterias for participants were as follows: (1) children with $\mathrm{CP}$ caused by neonatal hypoxic ischemic encephalopathy (HIE), premature birth, nuclear jaundice and chromosomal abnormalities among high-risk factors; (2) CMV infection had been treated with antiviral therapy; (3) standardized treatment had not been completed due to special conditions such as epilepsy.

Initially, 1132 children diagnosed with $\mathrm{CP}$ in the rehabilitation department of our hospital from January 2011 to December 2016 were collected. During the first round of screening, 803 children were excluded due to the etiologies of other factors (combined HIE: 113, premature delivery: 218 , nuclear jaundice: 52 , chromosome abnormalities: 109, brain developmental malformation: 143, central nervous system infection: 62, birth trauma: 35 , neonatal intracranial hemorrhage: 71). After the second round of screening, 182 children were excluded due to the incomplete data (negative CMV-IgG and IgM of children: 97, negative CMV-IgG and IgM of mother: 69, treated with antiviral therapy: 9 , incomplete clinical data: 7). Finally, 147 children diagnosed with $\mathrm{CP}$ were considered eligible for inclusions in the study. The flowchart of the data collection was presented in Fig. 1.

\section{Detection of CMV-DNA in urine}

Firstly, $1 \mathrm{ml}$ mid-stream clean-catch urinary of all participates were collected in the morning. Then the urinary sediment was collected for DNA extraction after 12,000 $\mathrm{r} / \mathrm{min}$ centrifugation for $5 \mathrm{~min}$.

CMV-DNA was evaluated by CMV fluorescence quantitative PCR (FQ-PCR). The kit was a product produced by the banner of the Daan gene. The fluocycle real-time quantitative PCR (Real-Time System) was produced by the company of BIO-RAD in USA. The detection of CMV-DNA in urine was carried strictly according to the instructions. The standard curve was set by using the software of the company of BIO-RAD in US. The number of copies of samples were computed by setting standard curves with different concentrations of reference substances.

\section{Standardized rehabilitation therapy}

All the children in the $\mathrm{CP}$ group received standardized rehabilitation treatment, including neurodevelopmental stimulation, muscle spasm/muscle excitation, cerebral circulation, meridian leveling, magnetic therapy, brain ultrasound, biofeedback, muscle strength training and neurotrophic drugs. The standardized treatment was composed of three courses of rehabilitation, and each course lasted for 21 days with an interval of one month.

\section{Therapeutic evaluation method \\ Gross motor function measure scale (GMFM)}

The scale of GMFM [36] was aimed to find out the gross motor state of CP children, the changes of motor function caused by the disease and intervention. GMFM has strong validity and reliability, which can quantitatively reflect the changed trend of gross motor function in $\mathrm{CP}$

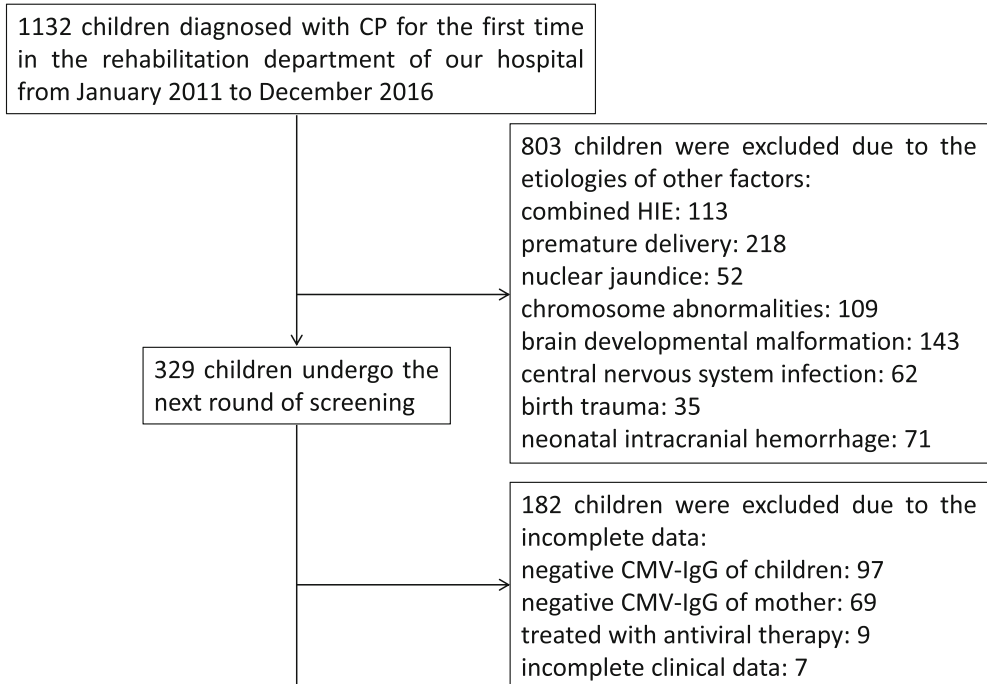

147 children diagnosed with CP were considered

eligible for inclusions in the study

Fig. 1 Flow diagram of data collection 
children. GMFM can be divided into five subscales with a total of 88 items (improved scale included 66 items). The five subscales are lying and turning, sitting, climbing and kneeling, standing, walking and jumping. The total score of the first subscale is 51 . The total score of the second subscale is 60 . The total score of the climbing and kneeling subscale is 42 . The total score of the standing subscale is 39 . The total score of the last subscale is 72. The results of GMFM is composed of the following parts: (1) original score: original score of all subscales; (2) total percentage: the sum of the percentage of the original score of all subscales/5; (3) monthly percentage: (total percentage of this time-previous total percentage)/ number of interval months; (4) relative percentage of month: (current monthly percentage/previous total percentage)* $100 \%$. The function of gross motor before and after treatment was evaluated by GMFM scale.

\section{Gesell developmental scale (GDS)}

The developmental quotient (DQ) was evaluated by the Gesell developmental scale (GDS) (1986) [37]. All CP subjects were evaluated by psychological evaluators who had experienced professional training and long-term practical experience. All testing items were carried out step by step in a specially designated psychological assessment environment. The normal range: $\geq 86$; the borderline state: $76 \sim 85$; the mild mental retardation: $55 \sim 75$; moderate mental retardation: $40 \sim 54$; severe mental retardation: $\leq 39$.

\section{Classification of CP}

According to the types of dyskinesia and the location of paralysis, there are six types: spastic quadriplegia, spastic diplegia, spastic hemiplegia, dyskinesia, ataxic and mixed. The above types of spasticity are classified according to ICD-10 and the latest international reports on CP.

\section{Statistical analysis}

Due to the great differences of CMV copy number, the logarithmic transformation was conducted. We performed $t$-test and variance analysis to compare the differences of CMV-DNA copy number, clinical typing and DQ of CP. Moreover, the associations between CMV-DNA copy number and the clinical characteristics of children with CP were assessed by the method of Pearson and Spearman correlation. The significance level was set at $P<0.05$.

\section{Results}

\section{Demographic and clinical characteristics}

The average age of CP group was 14.76 months (Male/female: 103/44). The average GDS score of CP was 73.29, and the average GMFM score was 62.01. The average age of control group was 15.10 months (male/female: 102/46). There were no significant group-differences of gender $(t=$
0.93, $P=0.35)$ and age $\left(x^{2}=0.07, P=0.79\right)$. A summary for the detailed demographic and clinical characteristics of all participants were presented in Table 1.

In the $\mathrm{CP}$ group, there were 14 cases $(9.6 \%)$ of spastic quadriplegia, 64 cases (43.5\%) of spastic diplegia, 38 cases $(25.9 \%)$ of spastic hemiplegia, 20 cases (13.6\%) of mixed type and 11 cases (7.5\%) of dyskinetic cerebral palsy. For MRI findings, there were 34 cases $(22.45 \%)$ of white matter damage, 24 cases $(15.65 \%)$ of brain dysplasia, 6 cases $(4.08 \%)$ of hydrocephalus, 9 cases $(7.48 \%)$ of encephalomalacia, 23 cases (15.6\%) of callosal dysplasia, 15 cases $(10.20 \%)$ of myelin hypoplasia and 36 cases (24.49\%) of normal structure.

\section{Differences of CMV copy number between groups}

The logarithmic transformation was conducted for the copy number of CMV. Compared with the control group $(-0.39 \pm 0.32)$, the CP group showed increased copy number of CMV $(0.76 \pm 1.20)(t=11.21 ; P=0.00)$ (Fig. 2).

\section{Differences of CMV copy number among different types of $\mathrm{CP}$}

The results of ANOVA analysis showed that there was significant difference of CMV copy number among different types of CP $(F=8.12 ; P=0.000006)$. Children with spastic quadriplegia $C P$ had higher rate of intrauterine CMV infection than other types of CP $(P=0.000003)$ (Fig. 3). However, there was no difference of intrauterine CMV infection rate among other types of CP (Fig. 3).

\section{Differences of $\mathrm{CMV}$ copy number among $\mathrm{CP}$ with different MRI findings}

ANOVA analysis demonstrated that there was no significant difference of CMV copy number among $\mathrm{CP}$ with different MRI findings $(F=1.10 ; P=0.39)$ (Fig. 4).

\section{Relationships between CMV infection and clinical symptoms}

Negative relationship was found between the copy number of CMV and the scores of GDS in the CP group $(r=-0.88$; $P=0.00$ ) (Fig. 5A). In addition, CMV copy number of the $\mathrm{CP}$ group showed negative relationship with the GMFM scores of the CP group $(r=-0.89 ; P=0.00)$ (Fig. $5 \mathrm{~B}$ ).

Moreover, all the children in the $\mathrm{CP}$ group received standardized rehabilitation treatment for 6 months. All children with CP were evaluated by the scale of GMFM after the standardized rehabilitation treatment. The differences of GMFM scores before and after the treatment were considered as the curative effect index of $\mathrm{CP}$ children. The copy number of CMV was found to be negatively associated with the increased scores of GMFM after the treatment $(r=-0.65 ; P=0.00)$ (Fig. $5 \mathrm{C})$. 
Table 1 Demographic and clinical characteristics of participates

\begin{tabular}{|c|c|c|c|c|}
\hline Variables & $\begin{array}{l}\text { CP group } \\
(n=147)\end{array}$ & Control group $(n=148)$ & $t / x^{2}$ value & $P$ value \\
\hline Average age (months) & $14.76 \pm 3.07$ & $15.10 \pm 3.21$ & 0.93 & $0.35^{\mathrm{a}}$ \\
\hline Sex (M/F) & $103 / 44$ & $102 / 46$ & 0.07 & $0.79^{b}$ \\
\hline Average GDS score & $73.29 \pm 12.73$ & - & - & - \\
\hline Average GMFM score & $62.01 \pm 16.99$ & - & - & - \\
\hline \multicolumn{5}{|l|}{ Classification of CP } \\
\hline Spastic quadriplegia & $14(9.6 \%)$ & - & - & - \\
\hline Spastic diplegia & $64(43.5 \%)$ & - & - & - \\
\hline Spastic hemiplegia & $38(25.9 \%)$ & - & - & - \\
\hline Mixed type & $20(13.6 \%)$ & - & - & - \\
\hline Dyskinetic cerebral palsy & $11(7.5 \%)$ & - & - & - \\
\hline Ataxia type & $2(1.4 \%)$ & - & - & - \\
\hline \multicolumn{5}{|l|}{ MRI findings } \\
\hline White matter damage & $34(22.45 \%)$ & - & - & - \\
\hline Brain dysplasia & $24(15.65 \%)$ & - & - & - \\
\hline Hydrocephalus & $6(4.08 \%)$ & - & - & - \\
\hline Encephalomalacia & $9(7.48 \%)$ & - & - & - \\
\hline Callosal dysplasia & $23(15.6 \%)$ & - & - & - \\
\hline Myelin hypoplasia & $15(10.20 \%)$ & - & - & - \\
\hline Normal structure & $24(24.49 \%)$ & - & - & - \\
\hline
\end{tabular}

$C P$ cerebral palsy, GMFM gross motor function measure scale, GDS Gesell developmental scale, $M R I$ magnetic resonance imaging. ${ }^{2} P$ value was based on the independent sample $t$ test. ${ }^{b} P$ value was based on the Pearson chi-square test. $P$ value was significant at $<0.05$

\section{Discussion}

CP is a common childhood physical disability of motor development, which is considered to be associated with a number of risk factors, including intrauterine CMV infection [35]. However, the relationships between CP and its clinical symptoms remain unknown. Our findings demonstrated that intrauterine CMV infection was a risk factor for $\mathrm{CP}$ and spastic quadriplegia $\mathrm{CP}$ patients who had higher rate of intrauterine CMV infection. The results

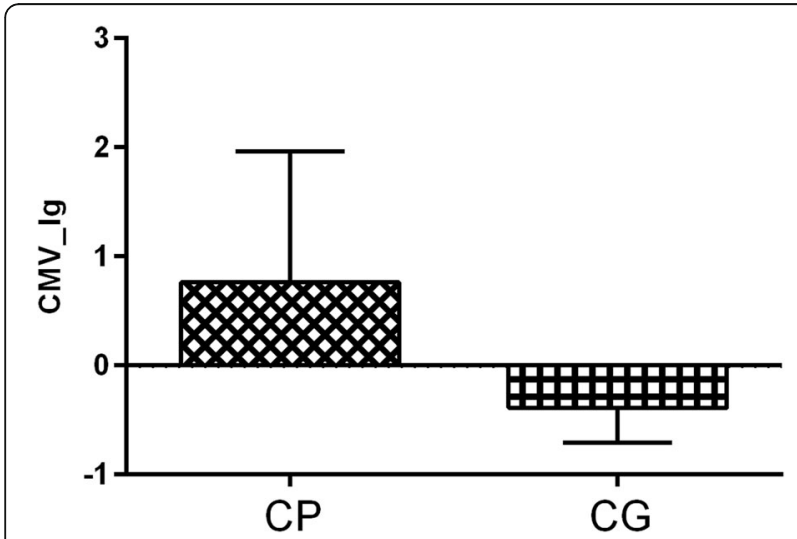

Fig. 2 Differences of CMV copy number between cerebral palsy group and control group also provided new knowledges about the associations between intrauterine CMV infection and the severity of clinical symptoms, the curative effect of standardized rehabilitation treatment of $\mathrm{CP}$.

Multiple risk factors are associated with the development of CP [38]. CMV infection occurs in a large number

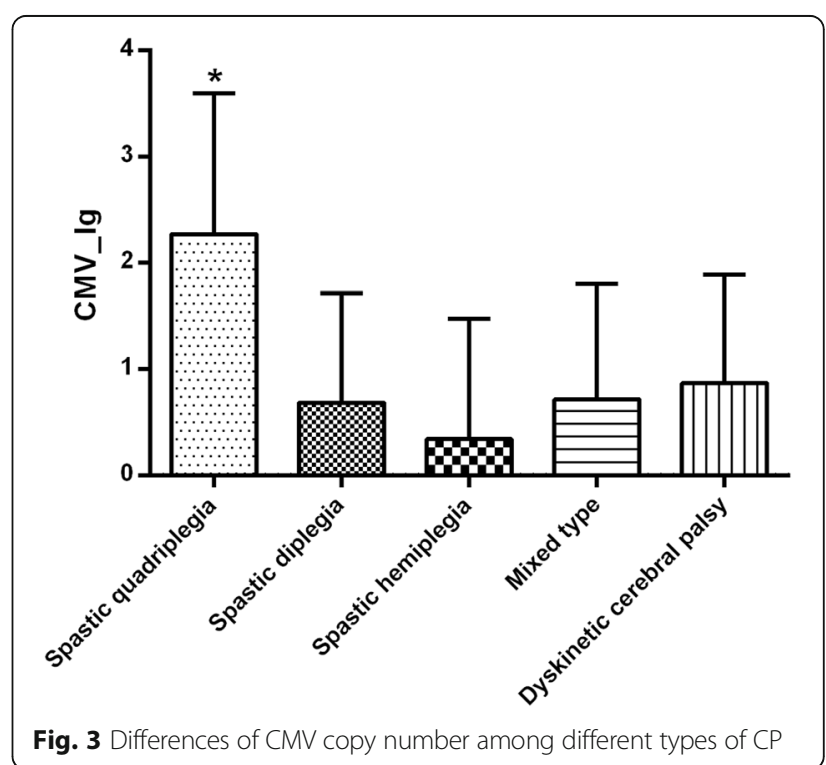




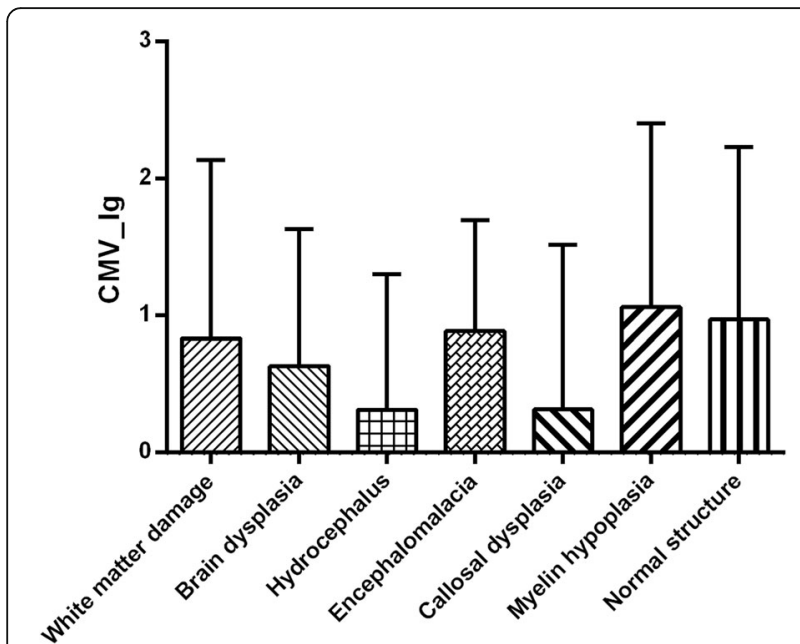

Fig. 4 Differences of CMV copy number among CP with different MRI findings

of newborn infants [39]. CMV infection can cause damage to the developing brain and the infants with CMV infection are at increased risk of permanent neurodevelopmental disabilities including CP [40]. Intrauterine CMV infection can cause neurodevelopmental impairments and it is a predictor of poor cognitive outcome [41]. Intrauterine CMV infection can also reflecte the negative effect of intrauterine CMV infection on early neurogenesis [42]. Previous studies showed that infection in the perinatal period was involved in causing unilateral spastic $\mathrm{CP}$, while neonatal infection was associated with bilateral spastic $\mathrm{CP}$ $[17,43]$. The results of our study showed that CP patients had increased copy number of CMV when compared with the control group. Therefore, intrauterine CMV infection may increase the risk of $\mathrm{CP}$. Infants with intrauterine CMV infection are more likely to have $\mathrm{CP}$ than children who do not have infection.

Infection is one of the most cases of post-neonatally acquired $\mathrm{CP}$ in developed countries [44]. Intrauterine exposure to infection in the latter stage of pregnancy is a strong risk factor for CP, especially CMV [45]. Moreover, neonatal infection increases the risk of spastic diplegia and the more severe form tetraplegia [17]. Previous study fund that infection was a risk factor for cerebrovascular ischemia [46]. The mechanism underlying this type of cerebrovascular ischemia may be the inflammatory, which stimulates coagulation and exacerbates the prothrombotic state during pregnancy and stimulate coagulation [47]. Maternal infection-related factors may activate an inflammatory response and infections should be taken seriously and treated accurately [48].

GMFM is a validated tool to measure gross motor function and evaluate the changes in the gross motor function of CP children [36]. In this study, spastic quadriplegia $\mathrm{CP}$ patients had higher rate of intrauterine CMV infection and negative associations were found between CMV and the of clinical symptoms of CP. In addition, intrauterine CMV infection was also negatively related with the curative effect of rehabilitation treatment in the CP group. Individuals with $\mathrm{CP}$ experience a range of impairments, especially variation in gross motor function [49]. The major characteristic of $\mathrm{CP}$ is the impaired development of gross motor function, which is related to the cognitive, auditory, visual defects of $\mathrm{CP}$ and is considered an indicator of prognosis [50]. Rehabilitation treatment has been used to improve the motor, cognitive and other function of $\mathrm{CP}$ patients [51]. In this study, prominent improvement was observed in $\mathrm{CP}$ children, which was reflected by the changes of GMFM score.

For the results of MRI findings, there were 24 cases (15.65\%) of brain dysplasia, 6 cases (4.08\%) of hydrocephalus. Previous neuroimging study showed that the dominant changes identified on MRI scans in children with CP were periventricular leukomalacia (42\%) and posthemorrhagic hydrocephalus (21\%) [52]. Another brain magnetic resonance imaging (MRI) study found that cortical dysplasia was observed in $27 \mathrm{CMV}$-positive patients (50.0\%). Therefore, CP was found to be associated with cortical dysplasia and marked intellectual disability. Moreover, CMV infection is considered as a
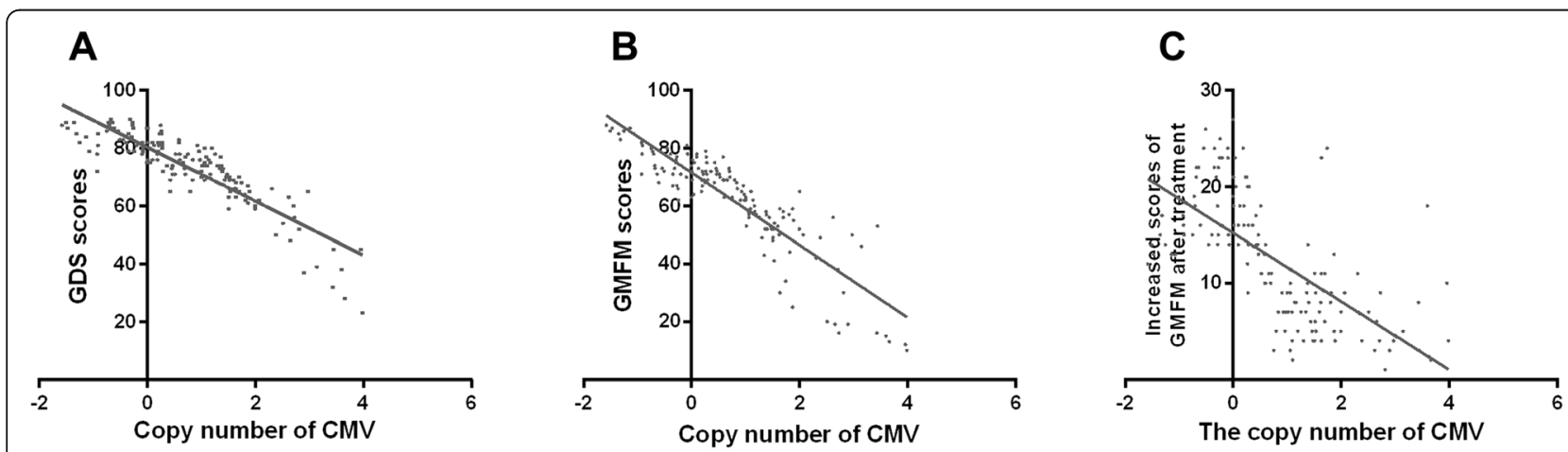

Fig. 5 Relationships between CMV infection and clinical symptoms 
cause of various neurological sequelae. All these reults suggeste that brain MRI investigations and the test of congenital CMV infection are important for making a diagnosis and formulating an intellectual prognosis of children with CP [53].

In this study, CMV-IgG and IgM in the serum of mother was positive identified by $\mathrm{TORCH}$ test during pregnancy, CMV-IgG and IgM in the serum of children was positive identified by TORCH test, and the urinary CMV-DNA data was also collected. Previous study suggested that detection of CMV-IgG and IgM in the serum of pregnant women was necessary for the diagnosis of maternal primary cytomegalovirus infection [54]. In addition, urine is also consider to be reliable specimens for neonatal cytomegalovirus screening using PCR [55]. According these evidences, the DNA of CMV in the urine and the anti-CMV IgG and IgM in the serum of mother and children can allow the diagnosis of intrauterine infection.

Intrauterine infection is considered as a risk factor for CP. Previous study demonstrated that congenital CMV infection in the newborn period was highly prevalent among children with $\mathrm{CP}$ [13]. Another study showed that congenital infection was uncommon in cases of $\mathrm{CP}$ and controls, however, CMV was significantly associated with CP [56]. It has been suggested the viruses may have the potential to cross the placenta and blood-brain barrier, infect the fetal brain and cause damage to developing neural tissue [57]. The viruses may have the potential to cross the placenta and blood-brain barrier, infect the fetal brain and cause damage to developing neural tissue [57]. However, further studies are needed to investigate the mechanisms and contribution of congenital CMV to the causal pathways to CP.

There are several limitations in our study. Firstly, this study is a retrospective study. Further large, prospective studies are needed in various types of $\mathrm{CP}$ involving different ages and severities. Secondly, we found that individuals with $\mathrm{CP}$ had different types of MRI findings. The method of diffusion tensor images (DTI) can characterize the damages of the white matter, especially motor tracts [58]. Therefore, the pattern of white matter abnormalities in the whole brain of CP and their correlations with the clinical scale metrics are needed to be assessed. Thirdly, large, population-based studies about the relationships between intrauterine CMV infection and clinical symptoms, white matter abnormalities in children with different types of $\mathrm{CP}$ are needed. Finally, as most of the children included in the present paper had 1 year of age only, the motor pattern and therefore the clinical classification of CP could change over time.

\section{Conclusion}

In conclusion, the results of our study demonstrated that individuals with $\mathrm{CP}$ have higher level of intrauterine
CMV infection. Moreover, the severity of CMV infection is negatively correlated with the functional outcomes of children with CP. Therefore, infection is a risk factor for the occurrence of $\mathrm{CP}$ and intrauterine $\mathrm{CMV}$ infection should be taken seriously and treated. Early control of infection may reduce the disability of children with $\mathrm{CP}$.

\section{Abbreviations \\ CP: cerebral palsy; CMV: Cytomegalovirus; GDS: Gesell developmental scale; MRI: Magnetic resonance imaging; HIE: Hypoxic ischemic encephalopathy; GDS: Gesell developmental scale; DQ: Developmental quotient}

\section{Acknowledgements \\ Not Applicable.}

\section{Authors' contributions}

$X H, Z L$ and $T J$ designed the experiments. $X X Y, Z X K$ and $Z M$ contributed to clinical data collection and assessment. $X H, Z L$ analyzed the results. $X H$, $Z \mathrm{~L}$ wrote the manuscript. $T \mathrm{~J}$ and $\mathrm{Z} X \mathrm{XK}$ approved the final manuscript. All authors have read and approved the manuscript.

\section{Funding}

The work was supported by the grants of: National Natural Science Foundation of China (No. 81501946; 81401864); Science and Technology Development Fund of Nanjing Medical University (No. NJMUB2019183; NJMUB2019188). The funding bodies played no role in the design of the study and collection, analysis, and interpretation of data and in writing the manuscript.

\section{Availability of data and materials}

The data used to support the findings of this study are available from the corresponding author upon request.

\section{Ethics approval and consent to participate}

This study was approved by the ethical commission of Children's Hospital of Nanjing Medical University (Program number (81501946): Version 1).

Additionally, written consents were obtained from parents or guardians on behalf of participants.

\section{Consent for publication}

Not Applicable.

\section{Competing interests}

We declare that we have no conflict of interest.

Received: 26 August 2020 Accepted: 1 December 2020

Published online: 08 December 2020

\section{References}

1. Aisen ML, Kerkovich D, Mast J, Mulroy S, Wren TA, Kay RM, Rethlefsen SA. Cerebral palsy: clinical care and neurological rehabilitation[J]. Lancet Neurol. 2011;10(9):844-52

2. Moreno-De-Luca A, Ledbetter DH, Martin CL. Genetic insights into the causes and classification of the cerebral palsies[J]. The lancet neurology. 2012;11(3):283-92

3. Holmström L, Vollmer B, Tedroff K, Islam M, Persson JK, Kits A, Forssberg H, Eliasson AC. Hand function in relation to brain lesions and corticomotorprojection pattern in children with unilateral cerebral palsy[J]. Developmental Medicine Child Neurology. 2010;52(2):145-52.

4. Reid SM, Dagia CD, Ditchfield MR, Carlin JB, Reddihough DS. Populationbased studies of brain imaging patterns in cerebral palsy[J]. Developmental Medicine Child Neurology. 2014;56(3):222-32.

5. Kim J-S, Han Z-A, Song DH, Oh H-M, Chung ME. Characteristics of dysphagia in children with cerebral palsy, related to gross motor function[J]. American journal of physical medicine rehabilitation. 2013;92(10):912-9.

6. Park ES, Sim EG, Rha D-W. Effect of upper limb deformities on gross motor and upper limb functions in children with spastic cerebral palsy[J]. Res Dev Disabil. 2011;32(6):2389-97. 
7. Ko J, Kim M. Reliability and responsiveness of the gross motor function measure-88 in children with cerebral palsy[J]. Physical therapy. 2013;93(3): 393-400.

8. Bottcher L. Children with spastic cerebral palsy, their cognitive functioning and social participation: a review[J]. Child Neuropsychol. 2010;16(3):209-28.

9. Christensen D, Van Naarden Braun K, Doernberg NS, Maenner MJ, Arneson CL, Durkin MS, Benedict RE, Kirby RS, Wingate MS, Fitzgerald R. Prevalence of cerebral palsy, co-occurring autism spectrum disorders, and motor functioning-A utism and D evelopmental D isabilities $M$ onitoring $N$ etwork, USA, 2008[J]. Developmental Medicine Child Neurology. 2014;56(1):59-65.

10. Miller JE, Pedersen LH, Streja E, Bech BH, Yeargin-Allsopp M, Van Naarden Braun K, Schendel DE, Christensen D, Uldall P, Olsen J. Maternal infections during pregnancy and cerebral palsy: a population-based cohort study[J]. Paediatr Perinat Epidemiol. 2013;27(6):542-52.

11. Streja E, Miller JE, Bech BH, Greene N, Pedersen LH, Yeargin-Allsopp M Braun KVN, Schendel DE, Christensen D, Uldall P. Congenital cerebral palsy and prenatal exposure to self-reported maternal infections, fever, or smoking[J]. American journal of obstetrics gynecology. 2013;209(4):332. e331-332. e310.

12. Bear JJ, Wu YW. Maternal infections during pregnancy and cerebral palsy in the child[J]. Pediatr Neurol. 2016;57:74-9.

13. Smithers-Sheedy H, Raynes-Greenow C, Badawi N, Fernandez MA, Kesson A, Mcintyre S, Leung K-C, Jones CA. Congenital cytomegalovirus among children with cerebral palsy[J]. J Pediatr, 2017, 181(267-71. e261.

14. Dakovic I, Da Graça Andrada M, Folha T, Neubauer D, Hollody K, Honold M, Horber V, Duranovic V, Bosnjak VM. Clinical features of cerebral palsy in children with symptomatic congenital cytomegalovirus infection[J]. european journal of paediatric neurology. 2014;18(5):618-23.

15. Smithers-Sheedy H, Raynes-Greenow C, Badawi N, Mcintyre S, Jones CA, Group ACPR. Congenital cytomegalovirus is associated with severe forms of cerebral palsy and female sex in a retrospective population-based study[J]. Developmental Medicine Child Neurology. 2014;56(9):846-52.

16. Ahlin K, Himmelmann K, Hagberg G, Kacerovsky M, Cobo T, Wennerholm UB, Jacobsson B. Non-infectious risk factors for different types of cerebral palsy in term-born babies: a population-based, case-control study[J]. BJOG: An International Journal of Obstetrics Gynaecology. 2013;120(6):724-31.

17. Ahlin K, Himmelmann K, Hagberg G, Kacerovsky M, Cobo T, Wennerholm UB, Jacobsson B. Cerebral palsy and perinatal infection in children born at term[J]. Obstetrics \& Gynecology. 2013;122(1):41-9.

18. Gotsch F, Romero R, Kusanovic JP, Mazaki-Tovi S, Pineles BL, Erez O, Espinoza J, Hassan SS. The fetal inflammatory response syndrome[J]. Clin Obstet Gynecol. 2007;50(3):652-83.

19. Guo R, Hou W, Dong Y, Yu Z, Stites J, Weiner CP. Brain injury caused by chronic fetal hypoxemia is mediated by inflammatory cascade activation[J]. Reproductive sciences. 2010;17(6):540-8.

20. Mallard C, Wang X. Infection-induced vulnerability of perinatal brain injury[J]. Neurology research international, 2012, 2012.

21. Zhao J, Chen $Y, X u Y, P i$ G. Effect of intrauterine infection on brain development and injury[J]. Int J Dev Neurosci. 2013;31(7):543-9.

22. Malaeb S, Dammann O. Fetal inflammatory response and brain injury in the preterm newborn[J]. J Child Neurol. 2009;24(9):1119-26.

23. Dammann O, Kuban KC, Leviton A. Perinatal infection, fetal inflammatory response, white matter damage, and cognitive limitations in children born preterm[J]. Ment Retard Dev Disabil Res Rev. 2002;8(1):46-50.

24. Silbereis JC, Huang EJ, Back SA, Rowitch DH. Towards improved animal models of neonatal white matter injury associated with cerebral palsy[j]. Disease models \& mechanisms. 2010;3(11-12):678-88.

25. Pannek K, Boyd RN, Fiori S, Guzzetta A, Rose SE. Assessment of the structural brain network reveals altered connectivity in children with unilateral cerebral palsy due to periventricular white matter lesions[J]. 5. Neurolmage: Clinical; 2014. pp. 84-92.

26. Fleiss B, Gressens P. Tertiary mechanisms of brain damage: a new hope for treatment of cerebral palsy?[J]. Lancet Neurol. 2012;11(6):556-66.

27. Staudt M. Brain plasticity following early life brain injury: insights from neuroimaging. in Seminars in perinatology. 2010. Elsevier.

28. Girard S, Kadhim H, Roy M, Lavoie K, Brochu M-E, Larouche A, Sébire G. Role of perinatal inflammation in cerebral palsy[J]. Pediatr Neurol. 2009; 40(3):168-74.

29. Yoon BH, Park CW, Chaiworapongsa T. Intrauterine infection and the development of cerebral palsy[J]. BJOG: an International Journal of Obstetrics Gynaecology. 2003;110:124-7.
30. Strunk T, Inder T, Wang X, Burgner D, Mallard C, Levy O. Infection-induced inflammation and cerebral injury in preterm infants[J]. The Lancet infectious diseases. 2014;14(8):751-62.

31. Vidak HK, Ivković TC, Jokić M, Spaventi R, Kapitanović S. The association between proinflammatory cytokine polymorphisms and cerebral palsy in very preterm infants[J]. Cytokine. 2012;58(1):57-64.

32. Leviton A, Allred EN, Kuban KC, Hecht JL, Onderdonk AB, O'shea TM, Paneth $\mathrm{N}$. Microbiologic and histologic characteristics of the extremely preterm infant's placenta predict white matter damage and later cerebral palsy. the ELGAN study[J]. Pediatr Res. 2010;67(1):95.

33. Terlizzi V, Improta F, Di Fraia T, Sanguigno E, D’amico A, Buono S, Raia V, Boccia G. Primary herpes virus infection and ischemic stroke in childhood: a new association?[J]. Journal of Clinical Neuroscience. 2014;21(9):1656-8.

34. Benoist G, Salomon L, Mohlo M, Suarez B, Jacquemard F, Ville $Y$. Cytomegalovirus-related fetal brain lesions: comparison between targeted ultrasound examination and magnetic resonance imaging[J]. Ultrasound in Obstetrics Gynecology: The Official Journal of the International Society of Ultrasound in Obstetrics Gynecology. 2008;32(7):900-5.

35. Sankar C, Mundkur N. Cerebral palsy-definition, classification, etiology and early diagnosis[J]. The Indian Journal of Pediatrics. 2005;72(10):865-8.

36. Russell DJ, Avery LM, Rosenbaum PL, Raina PS, Walter SD, Palisano RJ. Improved scaling of the gross motor function measure for children with cerebral palsy: evidence of reliability and validity[J]. Physical therapy. 2000; 80(9):873-85.

37. Bagnato SJ, Neisworth JT. Tracing developmental recovery from early brain injury[J]. Remedial Special Education. 1986;7(5):31-6.

38. Mcintyre S, Taitz D, Keogh J, Goldsmith S, Badawi N, Blair E. A systematic review of risk factors for cerebral palsy in children born at term in developed countries[J]. Developmental Medicine Child Neurology. 2013; 55(6):499-508.

39. Lanzieri TM, Dollard SC, Bialek SR, Grosse SD. Systematic review of the birth prevalence of congenital cytomegalovirus infection in developing countries[J]. International Journal of Infectious Diseases. 2014;22:44-8.

40. Manara R, Balao L, Baracchini C, Drigo P, D'elia R, Ruga EM. Brain magnetic resonance findings in symptomatic congenital cytomegalovirus infection[J]. Pediatric radiology. 2011;41(8):962-70.

41. Noyola DE, Demmler GJ, Nelson CT, Griesser C, Williamson WD, Atkins JT, Rozelle J, Turcich M, Llorente AM, Sellers-Vinson S. Early predictors of neurodevelopmental outcome in symptomatic congenital cytomegalovirus infection[J]. J Pediatr. 2001;138(3):325-31.

42. Giannattasio A, Bruzzese D, Di Costanzo P, Capone E, Romano A, D'amico A, Bravaccio C, Grande C, Capasso L, Raimondi F. Neuroimaging profiles and neurodevelopmental outcome in infants with congenital cytomegalovirus infection[J]. Pediatr Infect Dis J. 2018;37(10):1028-33.

43. Smilga A-S, Garfinkle J, Ng P, Andersen J, Buckley D, Fehlings D, Kirton A, Wood E, Van Rensburg E, Shevell M. Neonatal infection in children with cerebral palsy: a registry-based cohort study[J]. Pediatr Neurol. 2018;80:77-83.

44. Reid SM, Lanigan A, Reddihough DS. Post-neonatally acquired cerebral palsy in Victoria, Australia, 1970-1999[J]. J Paediatr Child Health. 2006;42(10):606-11.

45. Grether JK, Nelson KB, Walsh E, Willoughby RE, Redline RW. Intrauterine exposure to infection and risk of cerebral palsy in very preterm infants. Archives of pediatrics \& adolescent medicine. 2003;157(1):26-32.

46. Becher H, Grau A, Steindorf K, Buggle F, Hacke W. Previous infection and other risk factors for acute cerebrovascular ischaemia: attributable risks and the characterisation of high risk groups[J]. J Epidemiol Biostat. 2000;5(5): 277-83

47. Mccoll B, Allan S, Rothwell N. Systemic infection, inflammation and acute ischemic stroke[J]. Neuroscience. 2009;158(3):1049-61.

48. Romero R, Chaiworapongsa T, Espinoza J. Micronutrients and intrauterine infection, preterm birth and the fetal inflammatory response syndrome[J]. J Nutr. 2003;133(5):1668S-1673S.

49. Bartlett DJ, Hanna SE, Avery L, Stevenson RD, Galuppi B. Correlates of decline in gross motor capacity in adolescents with cerebral palsy in Gross Motor Function Classification System levels III to V: an exploratory study[J]. Developmental Medicine Child Neurology. 2010;52(7):e155-60.

50. Hanna SE, Rosenbaum PL, Bartlett DJ, Palisano RJ, Walter SD, Avery L, Russell DJ. Stability and decline in gross motor function among children and youth with cerebral palsy aged 2 to 21 years[J]. Developmental Medicine Child Neurology. 2009;51(4):295-302.

51. Novak I. Evidence-based diagnosis, health care, and rehabilitation for children with cerebral palsy[J]. J Child Neurol. 2014;29(8):1141-56. 
52. Morais BA, Solla DJF, Yamaki VN, Ferraciolli SF, Alves CAPF, Cardeal DD, Matushita $\mathrm{H}$, Teixeira MJ. Brain abnormalities in myelomeningocele patients[]]. Childs Nerv Syst. 2020;36(7):1507-13.

53. Uematsu M, Haginoya K, Kikuchi A, Hino-Fukuyo N, Ishii K, Shiihara T, Kato M, Kamei A, Kure S. Asymptomatic congenital cytomegalovirus infection with neurological sequelae: A retrospective study using umbilical cord[J]. Brain Dev. 2016;38(9):819-26.

54. Rawlinson WD, Boppana SB, Fowler KB, Kimberlin DW, Lazzarotto T, Alain S, Daly K, Doutré S, Gibson L, Giles ML, Greenlee J, Hamilton ST, Harrison GJ, Hui L, Jones CA, Palasanthiran P, Schleiss MR, Shand AW, van Zuylen WJ. Congenital cytomegalovirus infection in pregnancy and the neonate: consensus recommendations for prevention, diagnosis, and therapy[]]. Lancet Infect Dis. 2017;17(6):177-88.

55. Mussi-Pinhata MM, Yamamoto AY, Moura Brito RM, de Lima Isaac M, de Carvalho e Oliveira PF, Boppana S, Britt WJ. Birth prevalence and natural history of congenital cytomegalovirus infection in a highly seroimmune population[J]. Clin Infect Dis. 2009;49(4):522-8.

56. McMichael G, MacLennan A, Gibson C, Alvino E, Goldwater P, Haan E, Dekker G, Australian Collaborative Cerebral Palsy Research Group. Cytomegalovirus and Epstein-Barr virus may be associated with some cases of cerebral palsy[J]. J Matern Fetal Neonatal Med. 2012;25(10):2078-81.

57. Gibson CS, MacLennan AH, Goldwater PN, Haan EA, Priest K, Dekker GA, South Australian Cerebral Palsy Research Group. Neurotropic viruses and cerebral palsy: population based case-control study. BMJ. 2006;332:76-80.

58. Ishaque M, Manning JH, Woolsey MD, Franklin CG, Salinas FS, Fox PT. White matter tract pathology in pediatric anoxic brain injury from drowning[J]. American Journal of Neuroradiology. 2017;38(4):814-9.

\section{Publisher's Note}

Springer Nature remains neutral with regard to jurisdictional claims in published maps and institutional affiliations.

Ready to submit your research? Choose BMC and benefit from:

- fast, convenient online submission

- thorough peer review by experienced researchers in your field

- rapid publication on acceptance

- support for research data, including large and complex data types

- gold Open Access which fosters wider collaboration and increased citations

- maximum visibility for your research: over $100 \mathrm{M}$ website views per year

At $\mathrm{BMC}$, research is always in progress.

Learn more biomedcentral.com/submissions 